\title{
Adolescent mental health as a risk factor for adolescent smoking onset
}

This article was published in the following Dove Press journal:

Adolescent Health, Medicine and Therapeutics

25 February 201I

Number of times this article has been viewed

Jason M Hockenberry ${ }^{1,2}$

Edward J Timmons ${ }^{3}$

Mark W Vander Weg $2,4,5$

'Department of Health Management and Policy, College of Public Health,

University of lowa, IA, USA;

${ }^{2}$ Comprehensive Access and Delivery

Research and Evaluation Center

(CADRE), lowa City VA Medical

Center, IA, USA; ${ }^{3}$ School of Business, Saint Francis University, Loretto, PA,

USA; ${ }^{4}$ Department of Internal

Medicine, Carver College of Medicine,

University of lowa, IA, USA;

${ }^{5}$ Department of Psychology,

University of lowa, IA, USA
Correspondence: Jason M Hockenberry Department of Health Management and Policy, University of lowa College of Public Health, 200 Hawkins Dr, lowa City, IA 52242, USA

Tel + I 319356765 I

Fax +13193845125

Email jason-hockenberry@uiowa.edu
Abstract: Smoking continues to be a leading cause of preventable deaths and rates of trying cigarettes and progression to daily smoking among adolescents continues to remain high. A plethora of risk factors for smoking among adolescents has been addressed in the research literature. One that is gaining particular interest is the relationship between adolescent mental health and smoking (both initiation and progression). This paper reviews the evidence for adolescent mental health as a risk factor for cigarette smoking. We focus on the specific mental health conditions that have been more thoroughly addressed as possible risk factors in community-dwelling adolescents. We discuss the multiple hypotheses that have been posited as to the nature of the relationship between adolescent mental health and smoking, as well as detailing so called third factors that may account for the observed relationship. We highlight the contribution of the existing studies to the body of knowledge on this topic, as well as the limitations and open questions that remain as a result. We conclude with discussion of a broad research agenda going forward.

Keywords: depression, suicidal ideation, anxiety, nicotine, adolescents

\section{Introduction}

Smoking, and tobacco use in general, is the leading preventable cause of death in the United States. ${ }^{1}$ Most smokers begin using tobacco in adolescence. ${ }^{2}$ Of the youth who ever try cigarette smoking, approximately $36 \%$ progress to daily smoking by the end of high school. ${ }^{3}$ Moreover, nearly one-third of young smokers will eventually die from a smoking-related cause. ${ }^{4}$ Unfortunately, rates of adolescent smoking are still high. Although the prevalence of cigarette smoking among high school students declined during the late 1990s, the rate of decline slowed between 2003 and 2009..$^{5}$ In 2009, $19.5 \%$ of high school students reported smoking cigarettes during the past 30 days, with $7.3 \%$ reporting frequent use (defined as smoking on $\geq 20$ out of the last 30 days). ${ }^{5}$ Assessing factors associated with the risk of onset of smoking in adolescence has thus become an important research agenda because determining these factors can provide key insights into developing more effective prevention strategies and targeted interventions. One group of potentially predictive factors receiving a growing amount of attention is adolescent mental health conditions.

The focus of this review is on the evidence for adolescent mental health as a risk factor for the onset of smoking. We started by searching PubMed for the terms "adolescent" or "teen" combined with the terms "smoking" and "mental health", published through June 30, 2010 (746 studies). From the review of these abstracts, we identified four mental health symptoms which were commonly investigated in 
adolescents: depression, suicidal ideation, anxiety disorders, and attention deficit hyperactivity disorder. We adjusted our search parameters by replacing "mental health" in our original search with a search for each of the following: "depress*" (982 studies), "suicid*" (269 studies), "anxiety" (400 studies), and "hyperactiv*" OR "attention deficit" (169 studies) (*indicates wildcards which were used to include all variations of the term).

We then selected studies that have examined the link between mental illness and associated symptoms and the onset or progression (ie, transition from experimental to regular tobacco use or increased frequency or intensity) of smoking among noninstitutionalized adolescents. In selecting studies for the review we gave preference to studies with representative samples that employed methods or data that could provide insight into other factors that potentiate or mediate effects, or were longitudinal and could address temporal precedence between a mental health condition and smoking.

While this review focuses on the mental health as a risk factor for adolescent smoking, there is also substantial literature examining the opposite pathway. We have included discussion of select studies in this review to elucidate the complex relationship between smoking and adolescent mental health.

For each of the four mental health symptoms (depression, suicidal ideation, anxiety and attention deficit hyperactivity disorder), we discuss the literature in a chronological fashion to provide the reader insight into the progression in the scientific literature on mental health as a risk factor for smoking. We focus on the literature that arose in the previous 2 decades, though we use selected studies from the prior periods where they provide key insights. In the case of anxiety and suicidal ideation, where each has a complex clinical relationship with depression, we review the evidence base for these as a combined risk factor for adolescent onset of smoking. We conclude with a prescription for a research agenda in this area, and a discussion of the clinical and policy impetus for research on this topic of growing importance in adolescent health.

\section{Depression as a risk factor for smoking}

The association between smoking and depression across the age spectrum has long been established. ${ }^{6-9}$ Although some studies attempted to establish a direct causal link between smoking and depression, the "take home" message from the early literature that examined the relationship in adults was that there was a shared etiology. For example, continuous smokers were generally of lower socioeconomic status (SES), and lower SES was associated with increased prevalence of depression. ${ }^{6}$ Later studies pointed to genetic factors as being additional potential confounders. The interest in the relationship quickly expanded the focus of this literature to the adolescent population.

There has been rapid growth in the evidence base on the impact of mental health on smoking in the adolescent population, which has accelerated in the last decade. ${ }^{10-27}$ One can only speculate, but a likely motivation for this was the point made by Anda et $\mathrm{al}^{6}$ that cessation was more difficult for those with depression, and as such, the proportion of the smoking population with depressive symptoms was likely to grow. As such, the way to address comorbid smoking in individuals with depression may be to prevent smoking onset in the first place. Onset of both depression and smoking frequently occur in adolescence, and thus the need for understanding the dynamics of the two in that population..$^{28,29}$

Early in this literature on smoking and depression there was an understanding of the need to address this association using both cross-sectional and longitudinal data, if for no other reason than to attempt to establish temporal precedence. Brown and colleagues found a cross-sectional link between smoking and major depressive disorder (MDD) in a sample of 1709 adolescents aged 14-18 years, as well as evidence for increased smoking predicting MDD at a 1-year follow up (odds ratio [OR]: 1.89) and vice versa (OR: 2.04). ${ }^{10}$ Escobedo and colleagues examined responses of 7885 adolescents 12-18 years of age to the Teenage Attitudes and Practices Survey (a follow-up to the National Health Interview Survey) and found nonsmokers with depressive symptoms at baseline were more likely to initiate regular smoking (OR: 1.30) after adjusting for race, performance in school, presence of smokers in the household, and risk taking, while rates of cessation among smokers were not affected by the presence of depressive symptoms. ${ }^{12}$

Patton and colleagues assessed the association between cigarette smoking and gradient in severity of clinical depression in a longitudinal cohort of 14- and 15-year-old adolescents in Australia. ${ }^{13}$ Using the Clinical Interview Schedule, they found that those with scores $\geq 18$ were much more likely to engage in any smoking (OR: 2.0) or daily smoking (OR: 2.1) at baseline than those with scores $\leq 5$, with adjustments including age, gender, peer, and parent smoking status, dieting behavior, alcohol consumption, and sports participation. Interestingly, the effect of higher depression scores on smoking initiation were much more pronounced as the fraction of peers who smoked increased, 
suggesting reinforcing effects of peer smoking behavior in the presence of such symptoms.

Windle and Windle outlined the four primary hypotheses for the relationship between depression and smoking in teens - self medication, nicotine alteration of reward and mood neuroregulators, bidirectional effects, and common third (unobserved) factors. ${ }^{16}$ Using a short-term intensive longitudinal design (assessments conducted every 6 months over an 18-month interval) with additional metrics of possible confounders, they assessed the dynamics between depression and smoking in a sample of 1218 10th and 11th grade students. ${ }^{16}$ In using this design, the authors were able to reduce concerns of temporal precedence in longitudinal studies with longer inter-wave time periods, which allowed them to speak to the bidirectional hypothesis. They also addressed the issue of theoretically plausible confounders by including additional information that had not been employed in previous studies (including level of positive mood, task orientation, and flexibility). In addition, the authors' measurement approach for both depression and smoking allowed them to assess gradients in the effect of depression on smoking behavior similar to that in Patton et al. ${ }^{13}$ Results indicated that heavy and persistent smoking predicted increases in depressive symptoms over time, while heavy and persistent depressive symptoms also predicted increases in smoking behavior, thereby supporting a bidirectional or reciprocal influence model. These associations remained significant even after adjusting for a wide range of potentially confounding factors, suggesting that these "third variables" were not responsible for the observed relationship between smoking and depression.

Genetic predispositions to both depression and smoking had been noted as a potential third factor in this relationship, ${ }^{30}$ and was eventually examined empirically in adolescents. ${ }^{17}$ Audrain-McGovern and colleagues examined specific dopamine transporter and receptor variants' effects on smoking, while also collecting prospective data on depressive symptoms in the adolescents in their study. They found that a specific genetic variant (carrying at least one DRD2 A1 allele) increases the odds of smoking progression in those with existing exposure to nicotine (OR: 1.85). They also found a dose response relationship between the number of alleles and the Center for Epidemiologic Studies Depression Scale (CES-D) scores.

Lam and colleagues used a prospective longitudinal design involving a cohort of 1894 students aged $11-17$ years of age with two interview waves separated by twelve months in an attempt to establish temporal precedence. ${ }^{19}$ As in the previous studies of this type, they find evidence for temporal precedence from smoking to depressive symptoms and vice versa. ${ }^{19}$ Two things are of note in their analyses. First their analysis is void of adjustments for other factors known to be risk factors for both smoking and depression. The authors did control for demographics through the matching design, and because of their study population (Hong Kong Chinese adolescents), ethnic admixture may not be as much of a concern as in other studies; however, there are other socioeconomic factors and family behaviors that need to be considered when assessing these relationships. Second, the authors find that at the follow up interview those who were successful quitters had lower depressive symptoms than unsuccessful quitters and smokers who were not trying to quit. This is an important insight, because it suggests that difficulty quitting smoking may be tied to worse mental health, in this case depression.

Data from the first two waves of the National Adolescent Survey of Health (ADD Health) have been used in multiple studies attempting to address the temporal precedence and causality between smoking and depression. ${ }^{15,20,22,23}$ One of the analyses employed differences in mean prevalence of depression (as measured by the 18-item CES-D) by smoking status and gender between the two periods and suggests a coincidence of onset of depressive symptoms at onset of smoking and reduction of symptoms at quitting among females. ${ }^{22}$ The limitation of this is due partly to data and partly to analytical approach. First, as noted by the authors, the ADD Health data do not include information on depression history, thus one cannot rule out previous bouts of depression leading to eventual smoking onset or differences in the ability to quit successfully. Secondly, the data were part of a random sampling of schools, not individuals, and failure to account for shared predictors can yield misleading results. ${ }^{20}$ Indeed, once one introduces these additional factors into the analyses and makes adjustments using statistical techniques to deal with time-invariant unobservables (ie, respondent fixed effects), the magnitude of the impact of smoking on CES-D scale scores is, at best, clinically modest (the Duncan and Rees analysis suggests 1.25 points higher for females and 0.84 higher for males). ${ }^{20,23}$ To put this in context, Duncan and Rees noted that this is smaller than the score effect of changing the answer on one of the 18 survey items from "rarely" to "some of the time". ${ }^{20}$

From a statistical modeling perspective, the sharp reduction in the magnitude of the coefficient on smoking in the prediction of depressive symptom levels upon introduction of individual fixed effects suggests there may be substantial 
omitted variable bias in many of these early studies. Of particular concern are those that employ only crosssectional data and thus are not able to employ such methods, or contain limited adjustments for other factors associated with depression and/or smoking, ${ }^{14,15,18,27}$ In this spirit, the more recent literature addressing the relationship between depression and smoking in adolescents focuses on those modifying factors. ${ }^{24,26,27}$

School environment has been shown to be a mediating factor in the association between depression and smoking; specifically, the relationship between depression and smoking loses strength as the prevalence of smoking within a given school is reduced. ${ }^{24}$ This suggests that both social network effects and community norms may be important to consider in the relationship between smoking and depression. The mitigating effects of socioeconomic (father's education, living with parents), food intake and activity (drinking soft drinks, regular consumption of breakfast, and physical activity), and other risky health behaviors (using doping agents/anabolic steroids, consuming alcohol, and having sexual intercourse) have been assessed in a prospective study of 2489 15- and 18-year-old students in Norway. ${ }^{26}$ This study found no effect of baseline smoking on mental distress (measured using Hopkins Symptom Checklist, v 10 [HSCL-10]) at 3-year follow-up among males. Among females, there were statistically significant effects until baseline HSCL-10 scores were included in the model. In the fully specified model, the point estimates were slightly smaller than when only using a limited set of covariates, suggesting at least some impacts of unmeasured individual heterogeneity.

As another approach to addressing the concern that causality runs from smoking to depressive symptoms, rather than from depressive symptoms to smoking or through shared etiology, some of these studies have examined whether there is a dose-response relationship between smoking and depression. ${ }^{20,26,27}$ Claiming a physiologic link between smoking and depressive symptoms would logically also lead one to predict an association between increased smoking and increased symptoms. ${ }^{20}$ However, Duncan and Rees find that an additional pack of cigarettes per month only increases CES-D scores by 0.02 in males and 0.01 in females, a very small difference from a clinical perspective. ${ }^{20}$ Hockenberry and colleagues find no statistical difference in the probability of reporting depressive symptoms among smokers with a parent who smokes, despite the fact that this group smokes more per month and is more likely to be exposed to secondhand smoke in their household. ${ }^{27}$ In their fully specified models, Lien and colleagues do not appear to find statistically different impacts of smoking on mental distress at 3-year follow up between occasional and daily smokers. ${ }^{26}$ At a minimum, this lack of dose-response raises questions about the nature and plausibility of a causal physiologic relationship between smoking and depression.

\section{The biology of depression as a risk factor for adolescent smoking}

Biologically, there is support for the association between smoking and depression; however, even this evidence raises questions about causality. On one hand, nicotine promotes neuroadaptations that contribute to depression, while on the other it serves as a stimulant that may allow those experiencing depressive symptoms to relieve them, if only temporarily. ${ }^{27}$ Repeated nicotine exposure results in lower rates of biosynthesis of serotonin in rats, ${ }^{32,33}$ lower levels of serotonin in critical regions of the brain of deceased smokers, ${ }^{34}$ and serotonin levels have been found to be inversely related to smoking levels, though the latter study was among those with existing psychiatric diagnoses and based on a cross-sectional design. ${ }^{35}$ Conversely, Balfour and Ridley review the evidence from their animal studies and make an argument for the antidepressant properties of nicotine as a potential explanation for the observed relationship between smoking and depression. ${ }^{36}$ Their work suggests depression may potentiate progression in smoking, because stressful stimuli effects are pronounced in those with depression, and nicotine provides rapid relief from the stress effects.

Genetics likely play a strong role in the link between depression and smoking in adolescents. For example, Lerman and colleagues found that those with a specific genetic variant had a significant interaction between that variant and depression on the likelihood of smoking to reduce negative affect. ${ }^{30}$ As mentioned above, those with additional DRD2 A1 alleles were more likely to progress in smoking, and depression had a potentiating effect on this relationship. ${ }^{17}$ It is of paramount importance to realize, though, that the evidence on the effects of these genetics on smoking behavior and addiction is conditional upon nicotine exposure occurring in the first place. As such, even these biologic factors are subject to social influences, and thus peer and family influences, social norms, etc still play an important facilitating role to "trigger" this biological effect. 


\section{Suicidal ideation as a risk factor for smoking}

Suicidal ideation is common among individuals with mood disorders, of which depression is a subset. ${ }^{31}$ As such, it is not surprising that this literature on the relationship between depression and smoking eventually began to consider the possible link between suicidal ideation and smoking in adolescents..$^{27,37-41}$ To this point, the studies in this area have focused almost exclusively on smoking as a predictor of suicidal ideation, rather than suicidal ideation increasing the odds of smoking.

McGee and colleagues show that once one adjusts for the presence of high levels of stress, high levels of depressive symptoms, and low levels of parental attachment, the effect of smoking on suicidal ideation is not significant. ${ }^{37}$ Similar findings were confirmed by Kessler and colleagues where inclusion of Diagnostic and Statistical Manual of Mental Disorders, 4th Edition (DSM-IV) diagnoses reduced the magnitude of the relationship between smoking and suicidal ideation, and it was no longer statistically significant, ${ }^{38}$ suggesting that the association between smoking and suicidal ideation is largely mediated by depression status. The one study we are aware of that assessed the opposite effect, namely that suicidal ideation might lead to smoking, failed to find an effect of baseline suicidal ideation on smoking at follow up. ${ }^{39}$ Lastly, Hockenberry and colleagues find that the interaction between adolescent and parent smoking yields a key insight; namely, that those who smoke and do not have a parent who smokes are the individuals at higher odds for suicidal ideation relative to nonsmokers, suggesting likely third psychosocial factors, even beyond depression, as possible explanations for the correlation between smoking and suicidal ideation. ${ }^{27}$

\section{Anxiety as a risk factor for smoking}

The mounting evidence between anxiety and smoking has yielded slightly different insights than what has been noted in the literature on depression and smoking in adolescents. As in the case of depression, the early work in this area made attempts to disentangle the observed relationship between simultaneous anxiety and smoking. ${ }^{42}$ Throughout this early work on the relationship between mental illness and smoking, anxiety was often studied alongside depression/depressive symptoms using cross-sectional designs, which made determining temporal precedence and/or causality in the relationship between the three difficult (see for example Patton et $\mathrm{al}^{43}$ ).
Clarifying the nature of these relationships is further complicated by the high comorbidity between depression and anxiety ${ }^{44}$ and the difficulty of reliably distinguishing between the two sets of disorders. ${ }^{45}$ As a result, many have argued for a restructuring of the taxonomy of psychiatric disorders that would group many of the mood and anxiety disorders together into new categories. ${ }^{45-47}$ Nevertheless, we present the literature on depression and anxiety as though they were distinct constructs, although we acknowledge that there is considerable conceptual, symptomatic, and diagnostic overlap.

Subsequent work by Patton and colleagues examined the relationship longitudinally, though they did not distinguish between depression and anxiety in their measure. ${ }^{13,43} \mathrm{In}$ fact, prior to 2000, there does not appear to have been a study that considered anxiety as a potential precursor to the onset of regular smoking or nicotine dependence independent of depression. ${ }^{48}$ When Sonntag and colleagues examined the relationship between social anxiety and smoking in a 4-year longitudinal study of 3021 adolescents and young adults, they found that those with at least one social fear (but who did not meet DSM-IV criteria for social phobia) and those with DSM-IV-defined social phobia were more likely to exhibit nicotine dependence at baseline. ${ }^{49}$ Furthermore they found that nonusers with social fears were at higher odds of developing nicotine dependence at the 4-year follow-up, though those with social phobia were not at statistically higher odds of developing dependence. As the authors point out, this suggests that social network effects, or more pointedly, social modeling or peer pressure, may play a role in facilitating initiation among those with anxiety disorders. Specifically, the finding of no effect among those with phobias, who are more likely to avoid any social situations than those with anxiety, suggests the social context is important. ${ }^{49}$ Indeed, this is consistent with the conclusions of Patton and colleagues. ${ }^{13}$

Subsequently Breslau and colleagues found evidence of social phobia and post-traumatic stress leading to daily smoking among participants (aged 15-54 years) in the National Comorbidity Study.$^{50}$ Other studies over the last decade that have examined the onset of smoking as a result of the presence of an anxiety disorder found no relationship. ${ }^{51}$ While additional research has been done in the area of anxiety and smoking, the line of research examining anxiety as an independent risk factor for smoking in adolescents is less developed than that in the case of depression. Much of the other literature in the past decade either is cross sectional 
(making it difficult to get at temporal precedence or causality), ${ }^{52}$ finds that heavy smoking in adolescence predicts anxiety onset in later adolescence or early adulthood, ${ }^{53}$ or focuses more on anxiety associated with cessation or attempts at cessation. ${ }^{54,55}$ Despite this relatively less intensive investigation into anxiety as a factor in smoking onset, the issues inherent in examining this relationship differ very little from the case of depression and smoking. ${ }^{56}$ Namely, there are other factors, including familial and peer context, genetic factors and other unmeasured confounders, such as general preferences for future health, that need to be taken into account in future studies.

\section{Attention deficit hyperactivity disorder (ADHD) as a risk factor for smoking}

Almost as early as the work on the link between depression, anxiety and cigarette smoking a line of literature on the relationship between hyperactivity and smoking began. ${ }^{57,58}$ Interestingly this early study on hyperactivity and smoking was conducted in a way that suggested the theory behind the relationship was that of a pathway from hyperactivity to smoking, and adopted a longitudinal design to attempt to capture this. ${ }^{57,58}$ This early literature examining ADHD as a risk factor for smoking initiation in adolescence expanded, and has grown in the last 15 years, though perhaps not nearly as rapidly as the interest in smoking and depression. ${ }^{59-65}$

In the case of ADHD and smoking, the study designs have generally been more conducive to studying temporal precedence. Milberger and colleagues examined the effect of ADHD on cigarette smoking in a group of 237 males in early adolescence and found that ADHD predicted smoking at 4-year follow up, with and without adjusting for SES, IQ and other psychiatric comorbidity. ${ }^{59}$ Of particular interest was that they also found that at-risk siblings of those with ADHD also had a higher propensity for cigarette smoking, suggesting that temporal precedence may not indicate root causes, but rather familial situation potentially plays a more fundamental role in the causal pathway. ${ }^{60}$

Burke and colleagues examined whether particular aspects of ADHD (inattention and hyperactivity-impulsivity) were more likely to predict the onset of smoking and whether these associations remained following the inclusion of factors (eg, conduct disorder [CD]) known to be associated with both ADHD and substance use. ${ }^{62}$ This was a rather long (9-year) longitudinal study of 177 males between the ages of 7 and 12 years at study entry but was not designed to capture precedence. It included only those referred to a clinic, so the results of the impact of CD and inattentive behavior were conditional upon already exhibiting symptoms indicative of ADHD. However, it yields important insights into potential mechanisms and specific behavior components of ADHD which may put adolescents with ADHD at increased risk for smoking. Indeed analyses which considered whether there was CD present alongside ADHD diagnosis yielded insignificant results on the effect of ADHD on smoking. However, further unpacking of the symptoms of ADHD found that inattentive behavior was independently predictive even after adjusting for $\mathrm{CD}$. These analyses included parenting characteristics, ethnicity, family structure, number of siblings, maternal age at birth, SES, and urbanicity of residence. Ernst and colleagues confirm that aggression, which is related to $\mathrm{CD}$, was predictive of cigarette smoking onset. ${ }^{64}$ Their sample was rather small, however, and general diagnosis of ADHD did not differentiate smoking onset.

Fuemmeler and colleagues employed the ADD Health data (waves I and III) to examine whether ADHD in adolescents predicted regular smoking by adulthood. ${ }^{65}$ They found that symptoms of hyperactivity and $\mathrm{CD}$ in adolescents predicted regular smoking (ever having smoked at least one cigarette daily for 30 consecutive days) in adulthood after adjusting for family education attainment, being on public assistance, and demographics. The study did not yield clear implications for the relationship between these symptoms and experimentation (defined as ever having smoked a whole cigarette at least one time), so it is possible that ADHD did not differentiate nonsmoking and experimentation, only progression from either nonsmoking or experimentation to regular smoking, though the previous studies above suggest otherwise.

Within the ADHD research literature, the concern had been raised that treating ADHD with pharmacotherapy may actually raise the risk for smoking onset, the so-called gateway hypothesis. ${ }^{66}$ There is evidence that methylphenidate (a medication commonly used for the treatment of ADHD) increases the reinforcement value of smoking, ${ }^{67}$ which could contribute to the increased likelihood of smoking in this group. As in the case of depression, nicotine may also serve as an alternative to medication because it acts as a stimulant, raising the potential for the competing self medication hypothesis. Using longitudinal data with electronic diary information and cotinine measures, Whalen and colleagues demonstrated that adolescents with untreated ADHD smoked more than those that were undergoing treatment, and this finding was consistent across both self-report and cotinine 
measurement. ${ }^{66}$ This study suggests that untreated ADHD may lead to a higher likelihood or faster progression to smoking; although as the authors note, those who have untreated ADHD may have very different familial environments, so causality is not entirely clear.

\section{Adolescent mental health and smoking What do we know?}

Over the previous 2 decades, the literature on mental health as a potential risk factor for smoking has developed rapidly. Here we have focused on the relationship between depression, anxiety, ADHD, and smoking due in part to the fact that they are the conditions which have been well studied and in part because these mental health conditions are among the more prevalent among adolescents. This review is not systematic, mainly because we would argue the methods and data used to provide evidence in studies in this area are heterogenous (this obviously is not a topic that can be addressed by randomized controlled trial). Indeed there is not even agreement in the literature as to the pathway between adolescent mental health and smoking. Our intent has been to critically assess what has been observed about the link between adolescent mental health and smoking among community dwelling adolescents. Identifying the potential causal risk factors for smoking and addressing them could have a large impact on adolescent health, and more research focused on disentangling the causal factors is needed.

The literature on depression and smoking among adolescents is arguably the most well developed of the various mental health conditions, although a substantial proportion of these studies also examined anxiety due to the observed relationship between depression and anxiety even in the absence of smoking. Within this literature, the studies using longitudinal data have found temporal precedence for depression and resultant smoking and vice versa. However, studies that have adjusted for potential mediating or potentiating influences and use methods to control for unobservable factors attenuate the estimated relationship.

The literature on ADHD as a potential risk factor for smoking on the other hand has taken the tack that ADHD is an independent risk factor for smoking and generally found an association between ADHD and smoking onset or progression. The limitation is that many of these studies employ small samples and none that we are aware of deal with other unobserved potential factors that could drive both ADHD symptom development and smoking.

\section{A research agenda going forward}

While there is substantial literature in these areas, there is more to be done. The research in this area needs to move forward on multiple fronts. Of primary importance is using sampling strategies and study designs that allow for the use of statistical methods that are robust to concerns of omitted variable bias (including, but not limited to, fixed effects and instrumental variable modeling). A close second in terms of importance is the need for longitudinal studies with consistent sets of included covariates to assess potential mediators and potential pathways in the relationship between mental illness and smoking in adolescents. Without these, it is difficult to implement effective targeted clinical interventions, prevention strategies, or public health policies.

While we understand all data have their limitations, it is useful as a research community to know where we need substantially more understanding, so that adolescent health and as a consequence, adult health, might be improved. An ideal strategy would be to begin collecting longitudinal data on a large group of representative community dwelling individuals in late childhood and follow them through adolescence and into adulthood. Consistent measures of mental health using standardized and validated instruments as well as assessment of smoking experimentation, frequency and intensity would be of vital importance, as would be having them assessed frequently. Because genetics are potentially very important mediators/potentiators of both smoking and mental illness, having access to biologic data on these individuals would be highly preferable (including parents would be ideal, but modern family structure may preclude this and it would be nearly impossible to disentangle parental genetic impacts from family structure in cases where only one biologic parent was present). Beyond the need to adjust for genetic predisposition to both mental disease and addiction to nicotine conditional upon use, the random assignment of genetics can be used to disentangle causality in these relationships where study randomization to "treatment" (ie, smoking or mental illness) is not possible. ${ }^{68}$ Of other primary importance are family structure variables, demographics, SES, household education, and household behaviors (smokers and other substance abuse, as well as the presence of family members with mental illness). Beyond this, social network data, in line with social network and school environment data in the ADD Health in-home surveys, which has provided great insights into peer and other school level contextual effects in these relationships, would be warranted. Finally with geocoded data, researchers can also link in other potentially 
important variables including the supply of mental health services in a given area, built environment (ie, distance to cigarette retailers), state level attitudes toward tobacco use, state level variation in tobacco excise taxes and other factors known to impact tobacco consumption even among youth.

Indeed, the ADD Health data from the US have gone a long way to capturing many of the above suggested data points, and is beginning to generate insights. However, this study is basically a single cohort, captured at a time when this literature was in its infancy, so some measures of mental health and smoking leave something to be desired. Furthermore, as progress expands rapidly in the understanding of the genome and its influence on mental disease and behavior, broader arrays of genetic information will be necessary to assess the degree to which mental illness itself is a risk factor for smoking in adolescents. Given that $10 \%-15 \%$ of adolescents experience a major depressive episode alone, ${ }^{69}$ prevalence of diagnosed ADHD are at $9.5 \%$, and prevalence of smoking by age 18 years still hovers around $20 \%$, the importance of sorting out the sequencing of these illnesses and behaviors to improve lifetime health, education, and economic outcomes is no less than it was when this literature began to emerge 2-3 decades ago.

\section{Disclosure}

The authors report no conflicts of interest in this work.

\section{References}

1. Danaei G, Ding EL, Mozaffarian D, et al. The preventable causes of death in the United States: comparative risk assessment of dietary, lifestyle, and metabolic risk factors. PLoS Med. 2009;6:1-23.

2. Riordan M. Campaign for Tobacco-Free Kids Fact Sheet: Smoking and Kids. 2009. Available from: http://www.tobaccofreekids.org/research/ factsheets/pdf/0001.pdf. Accessed October 2010.

3. Centers for Disease Control and Prevention. Selected cigarette smoking initiation and quitting behaviors among high school students - United States, 1997. MMWR Morb Mortal Wkly Rep. 1998;47:385-389.

4. Centers for Disease Control and Prevention. Projected smoking-related deaths among youth - United States. MMWR Morb Mortal Wkly Rep. 1996;45:971-974.

5. Centers for Disease Control and Prevention. Cigarette use among high school students - United States, 1991-2009. MMWR Morb Mortal Wkly Rep. 2010;59;757-801.

6. Anda RF, Williamson DF, Escobedo LG, Mast EE, Giovino GA, Remington PL. Depression and the dynamics of smoking: a national perspective. JAMA. 1990;264:1541-1545.

7. Hughes JR, Hatsukami DK, Mitchell JE, Dahlgren LA. Prevalence of smoking among psychiatric outpatients. Am J Psychiatry. 1986;143: 993-997.

8. Kendler KS, Neale MC, MacLean CJ, Heath AC, Eaves LJ, Kessler RC. Smoking and major depression. A causal analysis. Arch Gen Psychiatry. 1993;50(1):36-43.

9. Breslau N, Peterson EL, Schultz LR, Chilcoat HD, Andreski P. Major depression and stages of smoking: a longitudinal investigation. Arch Gen Psychiatry. 1998;55:161-166.

10. Brown RA, Lewinsohn PM, Seeley JR, Wagner EF. Cigarette smoking, major depression, and other psychiatric disorders. J Am Acad of Child Adolesc Psychiatry. 1996;35:1602-1610.
11. Killen JD, Robinson TN, Haydel KF, et al. Prospective study of risk factors for the initiation of cigarette smoking. J Consult Clin Psychol. 1997;65:1011-1016.

12. Escobedo LG, Reddy M, Giovino GA. The relationship between depressive symptoms and cigarette smoking in US adolescents. Addiction. 1998;93(3):433-440.

13. Patton GC, Carlin JB, Coffey C, Wolfe R, Hibbert M, Bowes G. Depression, anxiety, and smoking initiation: a prospective study over 3 years. Am J Public Health. 1998;88(10):1518-1522.

14. Wu L, Anthony JC. Tobacco smoking and depressed mood in late childhood and early adolescence. Am J Public Health. 1999;89: 1837-1840.

15. Goodman E, Capitman J. Depressive symptoms and cigarette smoking among teens. Pediatrics. 2000;106:748-755.

16. Windle M, Windle RC. Depressive symptoms and cigarette smoking among middle adolescents: prospective associations and intrapersonal and interpersonal influences. J Consult Clin Psychol. 2001;69(2): 215-226.

17. Audrain-McGovern J, Lerman C, Wiley EP, Rodriguez D, Shields PG. Interacting effects of genetic predisposition and depression on adolescent smoking progression. Am J Psychiatry. 2004;161(7):1224-1230.

18. Haarasilta LM, Marttunen MJ, Kaprio JA, Aro HM. Correlates of depression in a representative nationwide sample of adolescents and young adults. Eur J Public Health. 2004;14:280-285.

19. Lam TH, Stewart SM, Ho SY, et al. Depressive symptoms and smoking among Hong Kong Chinese adolescents. Addiction. 2005;100(7): 1003-1011.

20. Duncan B, Rees D. Effect of smoking on depressive symptomatology: a reexamination of data from the National Longitudinal Study of Adolescent Health. Am J Epidemiol. 2005;162:461-470.

21. Poulin C, Hand D, Boudreau B, Santor D. Gender differences in the association between substance use and elevated depressive symptoms in a general adolescent population. Addiction. 2005;100:525-535.

22. Steuber TL, Danner F. Adolescent smoking and depression: which comes first? Addict Behav. 2006;31:133-136.

23. Munafò MR, Hitsman B, Rende R, Metcalfe C, Niaura R. Effects of progression to cigarette smoking on depressed mood in adolescents: evidence from the National Longitudinal Study of Adolescent Health. Addiction. 2007;103:162-171.

24. Chaiton MO, Zhang B. Environment modifies the association between depression symptoms and smoking among adolescents. Psychol Addict Behav. 2007;21(3):420-424.

25. Costello DM, Swendsen J, Rose JS, Dierker LC. Risk and protective factors associated with trajectories of depressed mood from adolescence to early adulthood. $J$ Consult Clin Psychol. 2008;76(2):173-183.

26. Lien L, Sagatun A, Heyerdahl S, Sogaard AJ, Bjertness E. Is the relationship between smoking and mental health influenced by other unhealthy lifestyle factors? Results from a 3-year follow-up study among adolescents in Oslo, Norway. J Adolesc Health. 2009;45:609-617.

27. Hockenberry JM, Timmons EJ, Vander Weg M. Smoking, parent smoking, depressed mood and suicidal ideation in teens. Nicotine Tobacco Res. 2010;12(3):235-242.

28. Gitanjali S, Iachan R, Scheidt PC, Overpeck MD, Sun W, Giedd JN. Prevalence of and risk factors for depressive symptoms among young adolescents. Arch Pediatr Adolesc Med. 2004;158:760-765.

29. Riordan M. Campaign for Tobacco-Free Kids Fact Sheet: Smoking and Kids. 2009. Available from: http://www.tobaccofreekids.org/research/ factsheets/pdf/0001.pdf. Accessed October 1, 2010

30. Lerman C, Main D, Audrain J, et al. Depression and self-medication with nicotine: the modifying influence of the dopamine D4 receptor gene. Health Psychol. 1998;17:56-62.

31. American Psychiatric Association. Diagnostic and Statistical Manual of Mental Disorders, 4th ed. Text Revision: DSM-IV-TR. Washington, DC: American Psychiatric Association; 2000.

32. Benwell ME, Balfour DJ. Effects of nicotine administration and its withdrawal on plasma corticosterone and brain 5-hydroxyindoles. Psychopharmacology. 1979;63:7-11. 
33. Benwell ME, Balfour DJ. Effects of chronic nicotine administration on the response to adaptation and stress. Psychopharmacology. 1982;76: $160-162$.

34. Benwell ME, Balfour DJ, Anderson JM. Smoking-associated changes in the serotonergic systems of discrete regions of human brain. Psychopharmacology. 1990;102:68-72.

35. Malone KM, Waternaux C, Haas GL, Cooper TB, Li S, Mann JJ. Cigarette smoking, suicidal behavior, and serotonin function in major psychiatric disorders. Am J Psychiatry. 2003;160:773-779.

36. Balfour DJK, Ridley DL. The effects of nicotine on neural pathways implicated in depression. A factor in nicotine addiction? Pharmacol Biochem Behav. 2000;66:79-85.

37. McGee R, Williams S, Nada-Raja S. Is cigarette smoking associated with suicidal ideation among young people? Am J Psychiatry. 2005;162: 619-620.

38. Kessler RC, Berglund PA, Borges G, et al. Smoking and suicidal behaviors in the National Comorbidity Survey. J Nerv Ment Dis. 2007;195:369-377.

39. Bronisch T, Höfler M, Lieb R. Smoking predicts suicidality: findings from a prospective community study. J Affect Disord. 2008;108:135-145.

40. Epstein JA, Spirito A. Risk factors for suicidality among a nationally representative sample of high school students. Suicide LifeThreat Behav. 2009;39(3):241-251.

41. Ahn MA, Kim KS, Ryu SY, Kang MG, Park J. Associations between smoking and alcohol drinking and suicidal behavior in Korean adolescents: Korea Youth Behavioral Risk Factor Surveillance, 2006. Prev Med. 2009;49:248-252.

42. Breslau N, Kilbey M, Andreski P. Nicotine dependence, major depression, and anxiety in young adults. Arch Gen Psychiatry. 1991;48:1069-1074.

43. Patton GC, Hibbert M, Rosier MJ, Carlin JB, Caust J, Bowes G. Is smoking associated with depression and anxiety in teenagers? Am J Pub Health. 1996;86:225-230.

44. Brown TA, Campbell LA, Lehman CL, Grisham JR, Mancill RB. Current and lifetime comorbidity of the DSM-IV anxiety and mood disorders in a large clinical sample. J Abnorm Psychol. 2001;110:585-599.

45. Brown TA, Barlow DH. A proposal for a dimensional classification system based on the shared features of the DSM-IV anxiety and mood disorders: implications for assessment and treatment. Psychol Assess. 2009;21:256-271.

46. Watson D. Rethinking the mood and anxiety disorders: a quantitative hierarchical model for DSM-IV. J Abnorm Psychol. 2005;114:522-536.

47. Clark LA, Watson D. Distress and fear disorders: an alternative empirically based taxonomy of the "mood" and "anxiety" disorders. $\mathrm{Br} J$ Psychiatry. 2006;189:481-483.

48. Morissette SB, Tull MT, Gulliver SB, Kamholz BW, Zimering RT. Anxiety, anxiety disorders, tobacco use, and nicotine: a cricitical review of interrelationships. Psychol Bull. 2007;133(2):245-272.

49. Sonntag H, Wittchen HU, Höfler M, Kessler RC, Stein MB. Are social fears and DSM-IV social anxiety disorder associated with smoking and nicotine dependence in adolescents and young adults. Eur Psychiatry. 2000;15:67-74.

50. Breslau N, Novak SP, Kessler RC. Psychiatric disorders and stages of smoking. Biol Psychiatry. 2004;55(1):69-76.

51. Dierker LC, Avenevoli S, Merikangas KR, Flaherty BP, Stolar M. Association between psychiatric disorders and the progression of tobacco use behaviors. J Am Acad Child Adolesc Psychiatry. 2001;40: 1159-1167.

Adolescent Health, Medicine and Therapeutics

\section{Publish your work in this journal}

Adolescent Health, Medicine and Therapeutics is an international, peer-reviewed, open access journal focusing on health, pathology, and treatment issues specific to the adolescent age group. All aspects of health maintenance, preventative measures and disease treatmen interventions are addressed within the journal and practitioners from
52. Dudas RB, Hans K, Barabas K. Anxiety, depression and smoking in schoolchildren - implications for smoking prevention. J R Soc Promot Health. 2005;125(2);87-92.

53. Johnson JG, Cohen P, Pine DS. Association between cigarette smoking and anxiety disorders during adolescence and early adulthood. JAMA. 2000;284(18):2348-2351.

54. Jacobsen LK, Krystal JH, Mencl WE, Westerveld M, Frost SJ, Pugh KR. Effects of smoking and smoking abstinence on cognition in adolescent tobacco smokers. Biol Psychiatry. 2005;57:56-66.

55. Pergadia ML, Agrawal A, Heath AC, Martin NG, Bucholz KK, Madden PAF. Nicotine withdrawal symptoms in adolescent and adult twins. Twin Res Hum Genet. 2010;13:359-369.

56. Morell HE, Cohen LM. Cigarette smoking, anxiety and depression. J Psychopathol Behav Assess. 2006;28(4):283-297.

57. Hartsough CS, Lambert NM. Pattern and progression of drug use among hyperactives and controls: a prospective short-term longitudinal study. J Child Psychol Psychiatry. 1987;28(4):543-553.

58. Barkley RA, Fischer M, Edelbrock CS, Smallish L. The adolescent outcome of hyperactive children diagnosed by research criteria: I. An 8-year prospective follow-up study. J Am Acad Child Adolesc Psychiatry. 1990;29:546-557.

59. Milberger S, Biederman J, Faraone SV, Chen L, Jones J. ADHD is Associated with early initiation of cigarette smoking in children and adolescents. J Am Acad Child Adolesc Psychiatry. 1997;36(1): 37-44.

60. Milberger S, Biederman J, Faraone SV, Chen L, Jones J. Further evidence of an association between attention deficit/hyperactivity disorder and cigarette smoking. Findings from a high-risk sample of siblings. Am J Addiction. 1997;6(3):205-217.

61. Lambert NM, Hartsough CS. Prospective study of tobacco smoking and substance dependencies among samples of ADHD and non-ADHD participants. J Learn Disabil. 1998;31:533-544.

62. Burke JD, Loeber R, Lahey BB. Which aspects of ADHD are associated with tobacco use in early adolescence? J Child Psychol Psychiatry. 2001;42(4):493-502.

63. Whalen CK, Jamner LD, Henker B, Delfino RJ, Lozano JM. The ADHD spectrum and everyday life: experience sampling of adolescent moods, activities, smoking and drinking. Child Dev. 2002;73(1): 209-227.

64. Ersnt M, Luckenbaugh DA, Moolchan ET, et al. Behavioral predictors of substance-use initiation in adolescents with and without attention- deficit/hyperactivity disorder. Pediatrics. 2006;117(6): 2030-2039.

65. Fuemmeler BF, Kollins SH, McClernon FJ. Attention deficit hyperactivity disorder symptoms predict nicotine dependence and progression to regular smoking from adolescence to adulthood. J Pediatric Psychology. 2007;32(10):1203-1213.

66. Whalen CK, Jamner LD, Henker B, Gehricke J-G, King PS. Is there a link between adolescent cigarette smoking and pharmacotherapy for ADHD? Psychol Addict Behav. 2003;17(4):332-335.

67. Stoops WW, Poole MM, Vansickel AR, Hays KA, Glaser PEA, Rush CR. Methylphenidate increases choice of cigarettes over money. Nicotine Tob Res. 2011;13(1):29-33.

68. Munafo MR, Araya R. Cigarette smoking and depression: a question of causation. Br J Psychiatry. 2010;196:425-426.

69. Young JF, Miller MR, Khan N. Screening and managing depression in adolescents. Adolesc Health Med Ther. 2010;1:87-95.

\section{Dovepress}

all disciplines are invited to submit their work as well as healthcare researchers and patient support groups.. The manuscript management system is completely online and includes a very quick and fair peerreview system. Visit http://www.dovepress.com/testimonials.php to read real quotes from published authors. 